\title{
Editorial
}

\section{Back to School?}

As I write this September editorial (a few weeks before publication), I can't help but wonder what the world of higher education and of academic libraries will look like when the issue is released.

Right now, it is the rush to the fall semester. Some institutions are holding virtual-only classes while others are planning face-to-face classes or some combination thereof. There are also institutions not opening at all and that will never open again due to the economic impacts of the pandemic.

The decisions to reopen (and how) are made at the highest level - by university presidents, chancellors, and regents or even governors. Undoubtedly, there are many factors that go into the decision-making process, with public safety being just one of them (but, arguably, the most important).

Academic libraries, as they always have, will pivot to engage in whatever environment is needed to provide access to resources and expertise, offer a safe study environment (as they are able), and remove barriers to information (made more difficult with COVID and other recent constraints).

As tens of thousands of students start to return to their universities (in my case, it is approaching 70,000 students with the majority opting for face-to-face instruction-for now), I look at the preparations for providing library services. They are probably much the same for librarians across the country who are faced with students taking onsite classes. Academic librarians are dedicated to providing a safe, information-rich study environment as well as access to resources and expertise to help students succeed and, as such, are consumed by every decision (both large and small):

- Measuring and remeasuring to figure out how many tables, desks, chairs can safely fit in a space

- Shifting and removing extraneous furniture (and any non-wipeable fabrics)

- Getting rid of high touch points from staplers and charging stands to Kleenex and brochures (while still worrying about public printers and door handles)

- Putting up Plexiglas around service desks so library staff can, theoretically, interact safely with patrons

- Setting up quarantine space and protocols for books while moving as much as possible to ebook format

- Distancing lab computers and setting up signage and processes to make sure they are cleaned between each use

- Removing hardware and devices from circulation (all the while acknowledging the dependence that students have on computers and wishing we could somehow fill the technology gap for those who don't have equal access)

- Training staff and student assistants to work in this new world (while feeling a large sense of responsibility that they, too, are on the front lines) 
There was training for everyone recently on how to engage with patrons in this new world, to encourage social distancing, and "enforce" mask-wearing in public spaces (which is mandated by many states and institutions). While it may seem very straightforward, it puts library staff right on the front line of the conflict between those who see COVID as a threat and those who see it as a hoax (and be grateful if you reside in a state that does not allow concealed carry on campuses).

There are a myriad of seemingly common tasks or issues that have the potential to escalate, but academic librarians will do what they can to meet the students' and faculty's needs. Having spent the last few weeks immersed, as many librarians have been, in these preparations, I can't help but wonder if it is going to be enough to hold back the COVID tide.

I think there is still the hope from some that this is just temporary-that COVID will fade and things will return to normal. But the truth is that baseline normal has irrevocably changed and that the only normal we may hope to attain is one that includes a sadly acceptable number of COVID deaths in the same breath as those we've come to expect from the flu. ${ }^{1}$

A recent column in Inside Higher Ed written by one of CERL's editorial board members, Chris Cox, was published back in June (which, in COVID time, seems a lifetime ago). Cox's column is a practical and insightful look at the inevitable changes to academic libraries stemming from COVID. If nothing else, this crisis has motivated organizations to identify and focus on what is critical and dispense with and eliminate all the minutiae. With shrinking budgets and dwindling resources, there are some hard decisions that are being made by academic libraries in particular about collections, services, and staffing (not to mention the number of legacy programs that will become COVID victims as well). I agree wholeheartedly with Cox that, while we may not know yet to what extent, everything is "Changed, Utterly Changed." ${ }^{2}$

In closing, I am left wondering if the November editorial will be written much as editorials were last Spring - from my kitchen where I was working from home because the pandemic had gotten bad enough to close the University. I certainly hope not.

\section{Notes}

1. Center for Disease Control and Prevention, "Past Seasons Estimated Influenza Disease Burden," last reviewed, January 2020, available online at: https:/www.cdc.gov/flu/about/burden/past-seasons.html.

2. Christopher Cox, "Changed, Changed Utterly," Inside Higher Ed, June 5, 2020, available online at https:// www.insidehighered.com/views/2020/06/05/academic-libraries-will-change-significant-ways-result-pandemicopinion. 